\title{
QUEM É O PROFISSIONAL DA INFORMAÇÃO?*
}

\author{
WHO IS THE INFORMATION PROFESSIONAL?
}

\author{
Maria das Graças TARGINO**
}

\begin{abstract}
RESUMO
Considerando a importância de se conhecer o perfil do profissional da informação como forma de fornecer a bibliotecários e cientistas da informação diretrizes para uma atuação compatível com o contexto mundial, em que impera a denominada sociedade da informação, após a necessária contextualização, discutem-se as questões conceituais que rondam a expressão - profissional da informação. A seguir, arrolam-se os requisitos básicos e as atribuições passíveis de serem exercidas por esses profissionais no século que se avizinha, o que pressupõe rever a formação dos bibliotecários, a partir da graduação.

Palavras-chave: PROFISSIONAL DA INFORMAÇÃO - CONCEITO; PROFISSIONAL DA INFORMAÇÃO - REQUISITOS; PROFISSIONAL DA INFORMAÇÃO - ATRIBUIÇÕES; BIBLIOTECÁRIOS - FORMAÇÃO.
\end{abstract}

\section{ABSTRACT}

Taking into consideration the importance of being familiar with the information professional profile, after his necessary context in the contemporary society, we discuss the ideas that hang around the expression - information professional. Following, we list the basic qualities liable to be carried out by this professional in the next century, what assumes to examine carefully the formation of librarians, since the graduation.

Keywords: INFORMATION PROFESSIONAL - CONCEPTS, INFORMATION PROFESSIONAL - REQUISITES, INFORMATION PROFESSIONAL - ASSIGNMENTS

\section{INTRODUÇÃO}

A princípio, julgamos essencial contextualizar o profissional da informação na atualidade, buscando compreender o porquê de sua emergência e em que circunstâncias isto ocorreu. Mesmo sem discorrer sobre os aspectos da história do livro e da biblioteca, acreditamos que, não obstante as denominações diversificadas ao longo dos tempos, a biblioteca é e sempre foi a instituição social a que compete exercer as funções de preservação e disseminação das informações e, por conseguinte, o bibliotecário, o profissional encarregado da concretização de tais objetivos.

\footnotetext{
(*) Palestra proferida no I INFORMAL - I Painel Alagoano em Ciência da Informação/I Ciclo de Debates em Ciência da Informação/I Ciclo de Debates sobre a Informação em Alagoas, Maceió - AL, 23 a 27/10/00.

(*) Doutora em Ciência da Informação, Universidade de Brasília - Professora Visitante da Universidade Federal do Piauí
} 
No entanto, a expressão - profissional da informação -, disseminada em nível mundial por teóricos, como Mason (1990) e Ponjuan (1993, 1995) e fortalecida pela Federação Internacional de Informação $e$ Documentação (FID), ao criar um grupo de estudo dedicado ao moderno profissional da informação (MPI), é relativamente nova, haja vista que se vincula à chamada sociedade da informação ou sociedade do conhecimento. Esta caracteriza-se pela ênfase dada à informação e ao seu acesso à informação, ocasionando transformações profundas nos sistemas de produção e consolidando o setor quaternário da economia, que incorpora todos os indivíduos, instituições, processos, produtos e atividades que fazem parte do ciclo de vida da informação desde a sua geração - inovação científica, artística e tecnológica - até o seu consumo - absorção e aplicação.

Especificamente, em termos de Brasil, o próprio Governo Federal, através do Ministério da Ciência e Tecnologia, vem se preocupando, cada vez mais, em estabelecer as diretrizes de um programa de ações rumo à sociedade da informação, o que está descrito no denominado "Livro Verde" (2000), que condensa propostas de ações abrangentes e ambiciosas, envolvendo instituições públicas e privadas, o que justifica sua repercussão no meio acadêmico e científico. O Programa Sociedade da Informação objetiva viabilizar um projeto de dimensão nacional para integrar o desenvolvimento e a utilização de serviços de computação, comunicação e informação e, portanto, de suas aplicações no âmbito da sociedade, de forma a consolidar a pesquisa e a educação (Miranda et al., 2000), assegurando à economia brasileira condições reais de competir no mercado mundial. Em síntese, é a busca de firmar a expressão sociedade da informação como modelo de processo desenvolvimentista social e econômico, em que aquisição, armazenamento, processamento, transmissão e disseminação de informação desempenham "... papel central na atividade econômica, na geração de novos conhecimentos, na criação de riqueza, na definição da qualidade de vida e satisfação das necessidades dos cidadãos e das suas práticas culturais" (Legey; Albagli, 2000, p. 1).

Em termos teóricos e práticos, o setor quaternário interage com o setor primário, secundário e terciário, resultando, de forma direta ou indireta, dessa contribuição. O avanço tecnológico é decisivo no processo de transformação sócio-cultural, mas é a sociedade que permite que isso ocorra, servindo de suporte para as inovações, uma vez que a tecnologia não tem autonomia, pois é instrumentalizada pelo homem, em meio a relações estabelecidas entre cultura, tecnologia e sociedade. Logo, é inviável estabelecer um modelo universal de sociedade da informação, sobretudo, no caso dos países não desenvolvidos, onde, ao lado dos beneficiados pelas inovações tecnológicas, grassam os marginalizados, com ênfase para os analfabetos, no sentido amplo do termo, aliados às vítimas do analfabetismo tecnológico.

Logo, o espaço quaternário determinado pelas novas tecnologias não é algo que se superpõe à condição humana, à cultura, à sociedade, à vida. Urge enfatizar menos a tecnologia e mais as necessidades sociais, mesmo sem repudiar o conhecimento como fundamento do poderio econômico dos povos. A qualidade de vida e as expectativas de transformações sociais e desenvolvimento econômico - padrão de vida, trabalho, lazer, educação e mercado - dependem, crucialmente, da informação. Sem negar o advento da sociedade da informação como decorrente da convergência entre os setores de telecomunicações e as novas tecnologias de informação e de comunicação, proporcionando maior competitividade às empresas e à economia dos países como um todo, é preciso assimilar que a sociedade da informação caracteriza-se pela possibilidade de acesso e capacidade de utilização da informação e do conhecimento, mas privilegia a qualidade de vida dos indivíduos e das coletividades. Exemplificando, apesar do caráter revolucionário do wap, tecnologia que permite o acesso sem fio à Internet via telefonia móvel ou convencional, sua consolidação depende, crucialmente, do nível de satisfação dos usuários, ao longo dos dias.

Sob tal perspectiva, tomando como referência o pensamento de Castells (2000, p. 78), afirmamos que são cinco os aspectos centrais do paradigma da tecnologia da informação, que representam a base material da sociedade da informação. Em primeiro lugar, a informação figura como sua matéria prima: "...são tecnologias para agir sobre a informação, não apenas informação para agir sobre a tecnologia..." A segunda característica refere-se à penetrabilidade dos efeitos das inovações tecnológicas. Como a informação integra o nosso cotidiano, todos os processos da existência individuais e coletivos são condicionados pelos novos meios tecnológicos. Em terceiro lugar, está a lógica de redes. Passível de ser implementada em qualquer tipo de processo e organização graças às novas tecnologias, a rede, enquanto configuração topológica, permite estruturar o não estruturado, embora preservando a flexibilidade, porquanto o não estruturado é a força maior da inovação das atividades humanas. Em se tratando do quarto aspecto, o paradigma da tecnologia da informação fundamenta-se na flexibilidade, ou seja, prima pela capacidade de reconfiguração, tanto de instituições, como de processos, o que é decisivo para a sociedade hodierna, marcada por constantes transformações. Finalmente, como antes 
delineado, a revolução tecnológica fundamenta-se na convergência de tecnologias específicas para um sistema altamente integrado: microeletrônica, telecomunicações, optoeletrônica e computadores articulam-se aos sistemas de informação.

Diante do exposto, afirmamos que o profissional da informação emerge pari passu com a sociedade da informação, que, por sua vez, apóia-se no avanço tecnológico, intimamente vinculado com o processo de globalização nos moldes atuais, porquanto a globalização pressupõe, irremediavelmente, acesso às novas tecnologias de informação e de comunicação, o que reforça a informação como mola propulsora das transformações que afetam a sociedade contemporânea. A verdade é que a globalização não é um fato novo. E mais, a globalização é um fenômeno ambivalente. Dentre suas inúmeras vantagens, enunciadas pela possibilidade de uma civilização transnacional com acesso igualitário a aplicações tecnológicas e a informações em todos os níveis, destacam-se: (a) expansão do comércio mundial, cujo crescimento é de cerca de 15 vezes em volume nos últimos 20 anos; (b) considerável fluxo de capital rumo aos mercados emergentes, ou seja, incremento de investimentos estrangeiros em países periféricos; (c) surgimento de zonas de alta tecnologia; e (d) redução dos custos das telecomunicações. Paradoxalmente, porém, vem sendo apontada como elemento esfacelador das fronteiras nacionais ou como instrumento de desemprego e miséria, agravando a incerteza econômica das nações e dos indivíduos frente às crises globais (Alcântara, 2000).

No entanto, estudos sintetizados pela fonte supracitada comprovam que a globalização não pode ser responsabilizada pela miséria que ainda impera, sobretudo, na África, sul da Ásia e América Latina. Ao contrário. Enquanto o Banco Mundial registra evolução econômica quando da globalização, no caso das populações absolutamente miseráveis, que sobrevivem com menos de um dólar por dia, pesquisa recente de uma organização norte-americana, Fundação Heritage, prova que os países mais pobres do mundo são exatamente os que permanecem à margem da globalização, quase sempre situados no continente africano. São nações que além de nada importarem e exportarem, não têm moeda transacionável e nem atraem capital externo. Em contraposição, nos países mais abertos à globalização, a renda per capita, grosso modo, é 10 vezes maior do que a daqueles que tentam proteger-se da economia mundializada. Ademais, ao que parece, o capitalismo "ostra" - nacionalismo exacerbado; fechamento das economias; culto à inflação; manutenção das reservas de mercado - concorre para muito da pobreza que os grupos antiglobalizantes, cada vez mais freqüentes, acusam a globalização de ser incapaz de amenizar ou solucionar.

Após posicionarmos o profissional da informação no contexto mundial, em que globalização e novas tecnologias marcam presença, no momento seguinte, discutimos as questões conceituais, estabelecendo requisitos, habilidades e atribuições passíveis de serem exercidas por esses profissionais no século que se avizinha, o que pressupõe rever a sua formação, a partir da graduação. Conhecer o perfil do profissional da informação propicia aos discentes e docentes de Biblioteconomia e/ou Ciência da Informação, bem como ao bibliotecário, ao cientista da informação e ao pesquisador, diretrizes para uma atuação mais adequada à realidade atual, além de lhe favorecer motivações para buscar, mais e mais, padrões pessoais e profissionais de excelência.

\section{AFINAL, QUEM É O PROFISSIONAL DA INFORMAÇĀO?}

Mas, afinal, quem é o profissional da informação? O que é ser profissional da informação? Analisemos, a partir do próprio termo, considerando as palavras constitutivas. Profissão, do latim professione, remete ao ato ou efeito de professar e, portanto, significa declaração ou confissão pública de uma crença, sentimento, opinião ou modo de ser, conduzindo à concepção ampla de atividade ou ocupação especializada, que requer preparo e formação. Daí, profissional designar quem exerce uma atividade por profissão ou ofício, isto é pessoa que exerce, como meio de vida, uma ocupação especializada.

Em se tratando de informação, a discussão é bem mais complexa e praticamente inesgotável. O termo adquire caráter "camaleônico", pois assume funções, papéis e níveis variados, sendo empregado de forma diversificada, constituindo juntamente com as concepções de dados, conhecimento e sabedoria, o que Mason (1990) chama de "hierarquia quádrupla". No entanto, independente da descrição detalhada acerca dessas questões, constante de nossa tese de doutoramento (Targino, 1998), de forma genérica, lembramos que se trata de um termo advindo do latim informare (originalmente, a ação de formar matéria, tal como pedra, madeira e couro), e que, segundo Wurman (1992, p. 42), tem como definição mais comum "...a ação de informar, formação ou moldagem da mente ou do caráter, treinamento instrução; ensinamento; comunicação de conhecimento instrutivo. "Sob tal ótica e de forma extremamente simplista, o profissional da 
informação é aquele cuja ocupação especializada consiste em lidar com a informação.

Ressaltamos a expressão - ocupação especializada. Isto porque, qualquer profissional para sobreviver no mercado de trabalho e até mesmo para manter relações com seus pares, é forçado a assimilar um corpo de conhecimentos que se amplia a cada segundo e a lidar, sistematicamente, com um número razoável de informações. A chance de enfrentar a competição do dia a dia com o que se aprendeu nas universidades, em qualquer área do conhecimento, é zero. Uma carreira profissional vai de 30 a 35 anos. No ritmo atual dos avanços tecnológicos e científicos, o indivíduo atravessa quatro ou cinco revoluções tecnológicas, o que agrava a chance de defasagem e exige extrema versatilidade, versatilidade esta, vinculada em nível de informação que detém, a tal ponto que Wurman (1992, p. 29) afirma: "Somos o que lemos. Tanto em nossa vida profissional quanto pessoal, somos julgados pela informação que utilizamos. A informação que ingerimos molda nossa personalidade, contribui para as idéias que formulamos e dá cor à nossa visão de mundo."

Mas, paradoxalmente, é este superdimensionamento da informação na sociedade da informação o maior responsável por um dos males do século - a ansiedade de informação -, resultante do fosso cada vez mais profundo entre o que o ser humano é capaz de apreender e o que acha que deveria compreender, diante das expectativas dos demais. Quase todos apresentam certo grau de ansiedade de informação, que se manifesta de formas variadas e inesperadas. É a surpresa diante da constatação de que é o único do grupo que desconhece as peripécias de certo ilusionista. É o desencanto de sentir-se excluído ante a discussão da obra do romancista que ganhou o Prêmio Nobel de Literatura. É o mal-estar pela falta de conhecimento diante do último escândalo político. É a impossibilidade de descrever, com segurança, o Projeto Genoma. E assim sucessivamente... Antes, durante a era industrial, o mundo era governado pelos recursos naturais. Hoje, é governado pela informação. Mas, se os recursos são finitos, a informação parece e é infinita. Mesmo assim, o homem contemporâneo é, inexoravelmente, julgado por seu padrão de consumo informativo.

No dia-a-dia, vemos que, qualquer pessoa, independente de sua área de atuação, precisa de informações, sem que isto o transforme em profissional da informação. Tanto pelo fato de tratar-se de um novo profissional (ou, pelo menos, assumindo novos papéis e funções), como por se referir a uma atividade que incorpora aspectos multidisciplinares, não consolidados nos cursos de graduação, o profissional da informação ainda possui conceituação frágil. Como conseqüência, há uma série de cognomes dispersos na literatura, tais como intérprete do cenário de informação; vendedor de serviços de informação; information packager, provedor e facilitador na transferência da informação; information broker. E mais, terminologias bem amplas, como manager, educador; tomador de decisões, estão sendo empregadas para nomear o profissional da informação, como Guimarães (1998) enumera.

Uma prova evidente da fragilidade conceitual é a pesquisa efetivada por Witter e divulgada em 1999. com a finalidade de identificar o perfil, ou seja, os traços característicos desse profissional, dentre bibliotecários e profissionais com formações distintas, como direito, letras, processamento de dados, administração, pedagogia, zootecnia, economia e engenharia civil, todos eles matriculados em curso de especialização sobre gerenciamento estratégico da informação. Quando solicitados a definir o profissional da informação, 30 depoentes apresentam 91 respostas. Dentre elas, o profissional que trabalha com a informação alcança o primeiro lugar, com 16 pontos, seguindo-se as alternativas: presta serviço de informação (14); é atualizado; visa à satisfação do usuário (ambas, com 12 menções); trabalha com suportes e meios variados (seis); é pesquisador (quatro). Daí em diante, as respostas são nitidamente dispersas e o que é preocupante, misturam aspectos conceituais com atributos, tais como: elo de ligação entre usuário e informação; facilitador de informação; competente; gerente de informação; crítico; paciente; compreensivo; dinâmico, atencioso; educado; responsável; atuante; social; envolvente; instigador; carismático; humilde; claro; colaborador etc.

De qualquer forma, as respostas mais significativas confirmam a nossa premissa, segundo a qual o profissional da informação refere-se àqueles que se dedicam à informação, o que implica atualização, capacidade de pesquisa e de manuseio de suportes variados, tendo em vista, sempre, as demandas informacionais do público. É o que justifica, cada vez mais, assegurar que profissional da informação é quem adquire informação registrada, não importa em que tipo de suporte, organiza, descreve, indexa, armazena, recupera e distribui essa informação, tanto em sua forma original, como em produtos elaborados a partir dela, excluindo os produtores de informação, quais sejam, os cientistas e tecnólogos.

Assim, todos os bibliotecários são ou deveriam ser profissionais da informação, mas nem todos os profissionais da informação são bibliotecários. A eles, somam-se documentalistas, arquivistas, museólogos, administradores, contadores, analistas de sistema, comunicólogos, jornalistas, publicitários, estatísticos, 
engenheiros de sistemas, sociólogos, educadores, dentre outros, com ênfase para ocupações emergentes, como webmasters e analistas de lógica industrial. A este respeito, Le Coadic (1996) agrupa esses profissionais em: (a) especialistas da informação; (b) empresários da informação; (c) cientistas da informação. No primeiro caso, estão aqueles que, sem atuarem em bibliotecas tradicionais, processam a informação, utilizando técnicas eletrônicas de informação - computadores e redes de telecomunicação -, priorizando mais a análise, comunicação e utilização da informação do que a armazenagem e conservação das coleções. Estão em diferentes locais, como no setor de marketing de uma firma, no departamento de investimentos de um banco, no laboratório de uma empresa química ou numa editora de produtos de informação e, de forma similar, recebem diferentes denominações - analistas da informação e/ou de documentos; gerentes da informação; planejadores de sistemas de informação etc.

Os empresários da informação agrupam os que criam empresas de fabricação e venda de produtos ou serviços de informação. Os produtos são diversificados - banco de informações especializadas; softwares; índices; catálogos etc. Os serviços de informação, também, pois fornecem informações segundo as necessidades dos clientes. No caso dos cientistas da informação, em geral, vinculados a universidades e institutos de pesquisa, dão ênfase ao estudo das propriedades da informação e ao desenvolvimento de novos sistemas e produtos de informação.

\section{PROFISSIONAL DA INFORMAÇÄO - REQUISITOS E HABILIDADES}

A partir de então, entendendo requisitos como condições essenciais à consecução de objetivos e fins determinados, o que, em última instância, significa habilidade ou capacidade para..., sintetizamos os requisitos básicos do profissional da informação. Para fins de sistematização, seguindo o raciocínio de Guimarães (1997, 1998), a princípio, os distribuímos em quatro blocos, não excludentes ou antagônicos: visão gerencial; capacidade de análise; criatividade; atualização. Diante da discutida relevância da informação na sociedade contemporânea, visão gerencial é atributo fundamental que permite ao profissional da informação tomar decisões, de forma racional e eficiente, diante de questões, como o custo da informação e o seu caráter estratégico, ao lado de capacidade de análise como subsídio para a referida tomada de decisão, face à diversificação de suportes, à multiplicidade de uso da informação e às demandas informacionais gradativamente mais singulares e individuais. Trata-se de adotar atitudes específicas, tais como, noção precisa de tempo e de espaço; conhecimento de condições financeiras e de investimentos em recursos humanos, engenharia e administração de fontes de informação e gestão eletrônica de documentos.

Por outro lado, criatividade é indispensável. Reiterando a tendência atual de supervalorizar o profissional criativo e inventivo, acreditamos que a inteligência é fundamental para o sucesso, mas não decisiva. A prova está que o número de pessoas altamente dotadas é bem superior ao de pessoas que se tornam eminentes. Por outro lado, se criatividade elevada pode ser considerada um tipo de inteligência ou advém de inteligência elevada, o oposto nem sempre ocorre, pois nem todas as aptidões que concorrem para o sucesso criativo são intelectuais. Algumas são perceptivas, donde se conclui que a criatividade inclui "ingredientes" cognitivos e perceptivos, como: originalidade, criticidade, liderança, sensibilidade diante de situações novas, flexibilidade e fluência, lembrando, como se diz, no cotidiano, que criatividade consiste, fundamentalmente, em buscar novas soluções para velhos problemas.

Também merece atenção a capacidade de atualização dentro do processo de educação continuada. Como visto, além de ser essencial a qualquer profissão, a atualização, que requer leitura, estudo e pesquisa, vai além dos conhecimentos técnicos. Se a alfabetização em novas tecnologias de informação e de comunicação é a condição primeira para que os profissionais da informação e, especificamente, os bibliotecários atuem como multiplicadores e alfabetizadores na sociedade do conhecimento, há outras habilidades que extrapolam a intimidade com o computador. É a motivação pessoal, o conhecimento de línguas estrangeiras; a tolerância no convívio com os demais; o dinamismo; a persistência; a visão interdisciplinar; o profissionalismo; a capacidade de comunicação e de fazer alianças; a competência; a responsabilidade; a capacidade de inovação, embora os requisitos ora enunciados, em termos genéricos, sejam básicos para qualquer outra profissão.

\section{PROFISSIONAL DA INFORMAÇÃO - ATRIBUIÇŌES}

Com base nos requisitos exigidos, o profissional da informação pode desempenhar uma série de atividades. Consensualmente, os bibliotecários centram suas ações em torno da: (a) seleção; (b) descrição; (c) interpretação; (d) disseminação; (e) preservação dos documentos e das informações, a tal ponto que o 
profissional da informação prossegue executando serviços, como empréstimo domiciliar; recuperação da informação; indexação e resumos; serviço de orientação e de treinamento de usuários e levantamentos bibliográficos on-line (FID, 1998). No entanto, concordamos com Tarapanoff (1999), quando diz que essas cinco funções primordiais e seus desdobramentos não vão desaparecer, mas, no espaço virtual, terão novas aplicações.

Então, preparar o profissional da informação para suprir as novas exigências de mercado, dinâmicas e instáveis, exige levantamentos de mercado sistemáticos, bem como estudos contínuos de oferta e identificação de perfis específicos de emprego, o que se chama, comumente, de job profiles ou job descriptions. Mesmo diante da conseqüente impossibilidade de precisar, com segurança, as atribuições do profissional da informação neste novo mercado, a autora acima citada arrola oportunidades de emprego para o novo profissional: pesquisador, especialista ou gerente da cultura; consultor de informação; gerente de bases e bancos de dados; especialista em computação e/ou softwares; editor no meio impresso e/ou na Internet; desenhista gráfico; desenhista em multimídia, imagem e vídeo; relações públicas; publicitário; tradutor; pesquisador de mercado; jornalista; produtor em estaçṍes de rádio e de televisão; especialista em tecnologia da informação; gerente de informação etc.

Na verdade, são terminologias ainda imprecisas. O que importa, porém, é que o profissional da informação, ao construir sua identidade frente a essas quase infinitas possibilidades de combinações entre profissões há muito consolidadas na sociedade atual, como a de publicitário, relações públicas, jornalista, editor e tradutor, não perca de vista a sua característica primordial de responsável pelo ciclo documentário e informacional, privilegiando a busca e o acesso a fontes de informação onde quer que estejam, com a finalidade precípua de suprir as necessidades informacionais de indivíduos e coletividades. Para tanto, bibliotecas e bibliotecários devem oferecer treinamentos e cursos para que o público tire proveito dos sistemas automatizados de recuperação da informação, vencendo barreiras, como as identificadas por Cuenca (1999), na capacitação de usuários em buscas informatizadas numa biblioteca médica da Universidade de São Paulo, dentre as quais, destaca a existência de variadas interfaces de busca para o acesso a bases de dados; tempo de busca; campos disponíveis para recuperação e a não familiaridade com o vocabulário técnico da área.

A este respeito, Le Coadic (1996) vai um pouco além e descreve algumas atividades informacionais do momento, com a ressalva de que, com certeza, nenhum de nós reúne condições de exercer todas elas, cabendo a cada um trilhar o seu próprio caminho, com base nas oportunidades de mercado, habilidades e, sobretudo, interesses motivacionais:

- avaliar, planejar, implantar e implementar redes de informação em empresas industriais;

- efetivar buscas manuais e informatizadas em serviços de documentação;

- implantar programas de gerenciamento de informação na automação de bibliotecas e instituições congêneres;

- implantar serviços eletrônicos de comunicação oral (a exemplo das videoconferências) e escrita (a exemplo do correio eletrônico), em diferentes empresas;

- preparar, resumir e editar informações em quaisquer áreas de conhecimento, o que requer domínio de informações especializadas, capacidade de interpretação e de redação de textos técnico-científicos;

- produzir programas audiovisuais e implantar sistemas de informação multimídia;

- gerenciar a formação de coleções das bibliotecas e similares, informatizando-as;

- editar revistas técnico-científicas;

- implantar a política orçamentária e de seleção de pessoal em centros de documentação e órgãos congêneres.

\section{PROFISSIONAL DA INFORMAÇÃO - FORMAÇÃO}

A formação do profissional da informação, no caso específico do bibliotecário, demanda reestruturação imediata dos cursos de graduação. Com base em considerações históricas sobre o ensino de Biblioteconomia no Brasil, da autoria de Guimarães (1997, 1998), apresentamos alguns pontos de reflexão. Em primeiro lugar, é preciso que os alunos estabeleçam contato permanente com as novas tecnologias de informação e de comunicação. Estas não devem figurar apenas como disciplina curricular ou conteúdo programático. Ao contrário. Precisam estar presentes como suporte ao ensino de temas diversificados, indo, por exemplo, da indexação ao estudo de usuário, da catalogação à geração de fontes de informação. Trata-se de uma visão ampla, coerente com o discurso da modernidade, quando Castells (2000) enfatiza que a inovação tecnológica não é um fato isolado. Integra as transformações registradas em estágios sucessivos da economia, com impactos significativos na redefinição 
da posição dos homens na sociedade, e, portanto, na formação das identidades culturais, e, inevitavelmente, na formação dos profissionais.

Um outro aspecto na formação do bibliotecário do século XXI vincula-se à visão gerencial na área de informação, antes mencionada, como pré-requisito do profissional da informação. De acordo com Morin (1999), ante o novo cenário da sociedade contemporânea, a única saída "honrosa" para decifrar o presente e se preparar para o futuro está na adoção de formas de pensar a realidade que extrapolem a linearidade, o que significa contextualizar, sempre, o fazer informacional, permitindo ao profissional identificar necessidades, planejar ações e gerenciar alternativas. Na mesma linha de raciocínio, está a abordagem dos suportes de informação como um todo, eliminando-se, de vez, a idéia da informação restritamente bibliográfica. Como visto, autores, como Ponjuan (1993, 1995); Tarapanoff (1999) e Witter (1999), acordam que o profissional da informação deve ter domínio sobre os diferentes suportes e meios físicos, e o papel passa a ser tão-somente um entre tantos outros.

Acrescentamos, também, seguindo os passos de Guimarães (1997, 1998), que os cursos de graduação não podem perder de vista a relevância da educação continuada para os seus graduandos, quer ao longo da formação básica, quer após a sua conclusão, atuando em conjunto com os organismos de classe e qualquer outra instituição. Conforme discussão anterior, a atualização é o elemento-chave para a sobrevivência do profissional e da profissão, em qualquer instância. Por outro lado, independente do Programa Institucional de Bolsas de Iniciação Científica (PIBIC) do Conselho Nacional de Desenvolvimento Científico e Tecnológico $(C N P q)$, os cursos de graduação em Biblioteconomia/ Ciência da Informação precisam adotar uma postura investigativa, valorizando a pesquisa como elemento vital à qualidade de ensino, e que pode abrir novos caminhos para o graduado.

Enfim, no que concerne à formação dos estudantes em Biblioteconomia/Ciência da Informação, são urgentes estruturas curriculares mais flexíveis, o que já vem sendo feito pela maioria das instituições. Reduzindo os pré-requisitos entre as disciplinas, devem comportar um número maior de matérias optativas e interdisciplinares, que permitam não apenas maior dinamismo, mas também a utilização de aportes metodológicos de outras áreas (como Administração, Arquivística, Lingüística, Comunicação, Psicologia, Sociologia), resultando num currículo de visão integradora, cujas partes estão intimamente relacionadas e todos os conteúdos caminham para o objetivo final, qual seja, o moderno profissional da informação. Aliás, o exemplo da Escola de Ciência da Informação da Universidade Federal de Minas Gerais, quando da criação do curso noturno de graduação, nos mesmos moldes do diurno, comprova que a redução da carga-horária das disciplinas obrigatórias e a conseqüente ampliação das optativas constituem a alternativa mais adequada para suprir as demandas da sociedade e as exigências do mercado de trabalho, condizentes com o ambiente informacional moderno, que requer perfis profissionais diversificados (Abreu; Campello, 2000).

Aqui, enfatizamos que a mudança de denominação dos cursos não basta para atender à formação de indivíduos competentes e capacitados para lidar com as características históricas, sociais e políticas da atualidade. A formação do profissional não está centrada apenas no alunado e no currículo, mas envolve uma série de outros fatores, com ênfase para a adaptação dos cursos à realidade, o aparelhamento dos laboratórios e, sobretudo, a capacitação e educação continuada dos docentes para a operacionalização das reestruturações curriculares, o que pressupõe pós-graduação, dedicação integral à docência, pesquisa e extensão, além de produção científica significativa. Em tempos de globalização, a competitividade significa, antes de tudo, competência profissional, que, por sua vez, equivale a "...novas formas de pensar, novas formas de interagir e novas formas de viver" (Franco, 1997, p. 9), o que justifica a crescente diversidade de professores de áreas afins nos cursos de graduação e pós-graduação na nossa área, enfatizando as características interdisciplinares do nosso campo de conhecimento e as atividades múltiplas que podem ser exercidas pelo profissional da informação.

\section{FINALIZANDO...}

Para os que alegam que a sociedade humana sempre se constituiu em sociedade da informação, resta-nos esclarecer que, nos moldes atuais, ela assume natureza revolucionária. Suas dimensões quase infinitas, seu caráter instantâneo, seu alcance global e seu volume imensurável de fluxo informacional transcendem o alcance e controle dos cidadãos, haja vista que a informação é, consensualmente, o fator determinante das transformações do século recém-findo, exatamente porque não obedece a delimitações espaciais, lingüísticas, culturais, políticas, atingindo as mais distintas facetas da vida do ser humano. Exige, assim, dos governos, que tomem para si a responsabilidade de equacionar o papel dessa nova sociedade em prol dos indivíduos comuns, envolvendo, ainda, instituições em 
todos os níveis, como bibliotecas, escolas, universidades, empresas públicas e privadas, associações de classe, conselhos federais e regionais, dentre outras, o que traz à tona, mais uma vez, os esforços do Grupo de Implantação do Programa Sociedade da Informação no Brasil.

Neste sentido, reiteramos que o profissional da informação emerge dentro do cenário da globalização e das novas tecnologias, substituindo o modelo de biblioteca centrado na disponibilidade, em que predomina o just in case, com ênfase no tamanho da coleção e na possibilidade do browsing real, por um novo modelo centrado na acessibilidade, em que prevalece o just in time, com destaque para o intercâmbio com as demais unidades de informação conectadas em rede e para o browsing virtual. São tentativas para consolidar a mudança de paradigma do acervo para a informação, do suporte físico para a informação, mas são tentativas irreversíveis, que se inserem no contexto da comunicação eletrônica, visando a fortalecer a biblioteca virtual como possibilidade real e não utopia.

Enfim, resta-nos tão somente lembrar que bibliotecas e bibliotecários têm sido profundamente influenciados pelas transformações responsáveis pela sociedade da informação, o que não nos permite permanecermos à margem do processo. Urge a adoção de novos caminhos para suprir as necessidades de informação do grande público, a partir da conscientização de que se este prefere a opção de consulta às redes eletrônicas na comodidade de seus lares, é preciso assumir o treinamento que permita ao usuário explorar a riqueza de possibilidades dos meios eletrônicos.

Da mesma forma que os editores comerciais, atentos para as bruscas mudanças do mercado, o bibliotecário precisa adotar a postura de moderno profissional de informação, a quem compete, conforme Mason (1990), fornecer a informação certa, da fonte certa, ao cliente certo, pelo meio certo, no momento certo e a um custo justo. Isto porque o usuário moderno dispõe, cada vez mais, de uma cultura informacional que lhe permite gerar bases de dados, navegar com facilidade nas redes eletrônicas de informação, efetivar sua busca bibliográfica e criar o seu corpo de conhecimentos, constituindo suas próprias bibliotecas virtuais, sem a intermediação do bibliotecário. É o momento de, como qualquer outro especialista, o bibliotecário atuar com criatividade, dinamismo, visão de mundo interdisciplinar/transdisciplinar, desenvolvendo habilidades na síntese da informação e conhecimentos nas áreas gerenciais e de políticas de informação, além do domínio pleno das novas tecnologias de informação. Neste sentido, passa a atuar mais como trainer, a quem compete treinar os usuários para que se tornem autônomos em suas buscas nos sistemas de informação automatizados, a exemplo da experiência vivenciada por Cuenca (1999), até porque, diante do fluxo informacional anárquico que caracteriza a Internet, se não existirem elementos facilitadores, chegar até a informação desejada pode tornar-se uma via-crucis.

Finalizando, tudo isto requer mudanças na formação do bibliotecário, desde a graduação, combatendo, prioritariamente, o enfoque muito especializado da profissão, quando o que se requer, cada vez mais, é uma visão ampla e polivalente do mundo, através de atuação pautada pelo profissionalismo no que se refere ao domínio das técnicas e processos da atividade informacional. Para tanto, são essenciais ações cotidianas e simples, como o domínio de um segundo idioma, a leitura sistemática de jornais e revistas informativas, a conscientização do homem como centro do universo, o olhar crítico mas não necessariamente demolidor ante a força dos meios de comunicação, a possibilidade de estágios em realidades distintas, até porque a experiência não pode ser preterida em prol de um diploma, em qualquer nível. Em outras palavras, parafraseando Tarapanoff (1999), precisamos, todos nós, adotar o lema de Geraldo Vandré, eternizado em sua canção A Caminhada, quando diz: "Quem sabe faz a hora, não espera acontecer", sem, no entanto, perder de vista a realidade brasileira, cujo desequilíbrio econômico e disparidades sociais inter-regionais dão origem a brasis distintos, onde uma parcela significativa da população continua distante da modernização tecnológica e de suas possibilidades, ansiando, quando muito, pelo acesso a livros e a simples salas de leitura.

\section{REFERÊNCIAS BIBLIOGRÁFICAS}

ABREU, V. L. F. G.; CAMPELLO, B. S. Graduação em biblioteconomia: a formação do profissional da informação para o século XXI. Perspectivas em Ciência da Informação, Belo Horizonte, v. 5, n. especial, p. 93-103, 2000.

ALCÂNTARA E. A grande fogueira das bobagens. Veja, São Paulo, v. 33, n. 40, p. 192-194, 4 out. 2000.

CASTELLS, M. A sociedade em rede. 3. ed. São Paulo: Paz e Terra, 2000. 617 p. (A era da informação: economia, sociedade e cultura, 1 ).

CRICKMAN, R. D. The emerging information professional. Library Trends, [s. I.), v. 28, n. 2, p. 311-327, fall 1979.

CUENCA, A. M. B. O usuário final da busca informatizada: avaliação da capacitação no acesso a bases de dados em biblioteca acadêmica. Ciência da Informação, Brasília, v. 28, n. 3, p. 291-299, set./dez. 1999. 
FRANCO, M. A. Internet: reflexões filosóficas de um informata. Transinformação, Campinas, v. 9, n. 2, p. 1-11 maio/ago. 1997. Disponível em: <http://www.puccamp.br/ $\sim$ biblio/franco>. Acesso em: 27 jul. 2000.

GUIMARÃES, J. A. C. Moderno profissional da informação: a formação, o mercado e o exercício profissional no Brasil. CBF [Conselho Federal de Biblioteconomia] Informa, Brasília, v. 3, n. 2, p. 6-7, abr. 1998.

Moderno profissional da informação: elementos para sua formação no Brasil. Transinformação, Campinas, v. 9, n. 1, p. 124-140, jan./abr. 1997.

INTERNATIONAL FEDERATION OF INFORMATION AND DOCUMENTATION (FID). Towards the new information society of tomorrow: innovations, challenges and impact. In: FID CONFERENCE AND CONGRESS, 49., 1998, New Delhi. [Papers...]. New Delhi: Indian National Scientific Documentation Center, 1998.

LE COADIC, Y.-F. A ciência da informação. Brasília: Briquet de Lemos/Livros, 1996. 119 p.

LEGEY, L.-R.; ALBAGLI, S. Construindo a sociedade da informação no Brasil: uma nova agenda. DataGramaZero: Revista de Ciência da Informação, v. 1, n. 5, p. 1-16, out. 2000. (art. no 2). Disponível em: <http://www.dgzero.org>. Acesso em: 22 jan. 2001.

O LIVRO Verde: a sociedade da informação no Brasil. Brasília: Soclnfo, 2000.154 f. (Digitado).
MASON, R. O. What is an information professional? Journal of Education for Library and Information Science, Arlington, v. 31, n. 2, p. 122-138, 1990.

MIRANDA, A. L. C. de et al. Os conteúdos e a sociedade da informação no Brasil. DataGramaZero: Ciência da Informação, v. 1, n. 5, p. 1-30, out. 2000. (art. no 3). Disponível em:<http://www.dgzero.org>. Acesso em: 20 jan. 2001.

MORIN, E. La méthode 4. Paris: Ed. Seuil, 1999.

PONJUAN, G. Does the modern information professional have a life cycle? FID News Bulletin, [s. I.], v. 43, n. 3, p. 61, mar. 1993.

. La nueva postura del profesional de información. In: COBIB, 3., São Paulo, 1995.11 p. (Digitado).

TARGINO, M. das G. Comunicação científica: o artigo de periódico nas atividades de ensino e pesquisa do docente universitário brasileiro na pós-graduação. 1998. 387 f. Tese (Doutorado em Ciência da Informação) - Depar-tamento de Ciência da Informação e Documentação da Faculdade de Estudos Sociais Aplicados da Universidade de Brasília, 1998.

TARAPANOFF, K. O profissional da informação e a sociedade do conhecimento: desafios e oportunidades. Transinformação, Campinas, v. 11, n. 1, p. 27-38, jan./abr. 1999.

WITTER, G. P. Profissional da informação: caracterização e busca de instrumentos para avaliação. Transinformação, Campinas, v. 11, n. 1, p. 47-53, jan./abr. 1999.

WURMAN, R. S. Ansiedade de informação. São Paulo: Cultura, 1992. 380 p. 